\title{
甲烷与三氯化铁的光化学反应在环境温度下实现 甲烷的选择性氯化反应
}

\author{
霍尚飞陈鸿左伟伟* \\ (东华大学材料科学与工程学院 纤维材料改性国家重点实验室 上海 201620)
}

\begin{abstract}
摘要 在温和条件下选择性活化与转化甲烷具有可观的经济效益, 但同时也是难点. 报道在环境温度条件下, 无水三 氯化铁 $\left(\mathrm{FeCl}_{3}\right)$ 与甲烷在环境温度下的光化学反应, 这是一种有效的选择性活化甲烷生成一氯甲烷的方法. 在 $300 \mathrm{~W}$ 的 高压录灯或者太阳光的照射下，由甲烷转化的产物为单一的一氯甲烷，而没有其它多氯代物，最大初始生成效率为 43 $\mathrm{g}_{\mathrm{MeCl}} \bullet\left(\mathrm{kg}_{\mathrm{Fe}} \bullet \mathrm{h}\right)^{-1}$. 氯化铁既作为氯自由基源，也作为氧化剂，并在反应中被还原为氯化亚铁. 高压录灯功率增加以及氯 化铁浓度增加都会加快初始反应速率. 而反应温度以及甲烷的压力对反应的初始速率影响很小. 氯甲烷可以被水解为 甲醇，亚铁在空气以及盐酸存在下也可以被重新氧化为三价铁，从而完成铁和氯的循环.
\end{abstract}

关键词 $\mathrm{C}-\mathrm{H}$ 活化; 甲烷活化与转化; 金属催化合成反应; 光催化

\section{Selective Chlorination of Methane Photochemically Mediated by Ferric Chloride at Ambient Temperature}

\author{
Huo, Shangfei Chen, Hong Zuo, Weiwei* \\ (State Key Laboratory for Modification of Chemical Fibers and Polymer Materials, College of Materials \\ Science and Engineering, Donghua University, Shanghai 201620)
}

\begin{abstract}
Selective activation of methane under mild conditions to produce functionalized products is highly lucrative but remains challenging. The photochemical reaction of anhydrous ferric chloride $\left(\mathrm{FeCl}_{3}\right)$ with methane at ambient temperature is an efficient process to selectively chlorinate methane to methyl chloride. An exclusive formation of methyl chloride instead of other multi-chlorinated products is observed, and a maximum initial productivity of $43 \mathrm{~g}_{\mathrm{MeCl}} \bullet\left(\mathrm{kg}_{\mathrm{Fe}} \bullet \mathrm{h}\right)^{-1}$ was obtained under irradiation with a 300-watt high-pressure mercury lamp or solar light. Ferric chloride functions both as the source of reactive chlorine radicals and as the oxidant, and it was concomitantly reduced to ferrous chloride. The reaction rate increases with the power of the lamp and the concentration of ferric chloride. Interestingly, the reaction temperature from 25 to $75{ }^{\circ} \mathrm{C}$ and the methane pressure in the range of $1 \sim 4 \mathrm{MPa}$ had little influence on the reaction rate. Methyl chloride was hydrolyzed to methanol with elimination of hydrogen chloride, and the ferrous product was re-oxidized to the ferric analog by oxygen in the air in the presence of hydrogen chloride, thus completing the loop of both iron and chlorine.

Keywords C-H activation; methane activation and functionalization; metal-catalyzed synthetic reaction; photocatalysis
\end{abstract}

\section{Introduction}

With increasing explored reserves in the past 30 years, ${ }^{[1]}$ natural gas could become an economical and clean substitute to dwindling petroleum as the feedstock for fuels and value-added chemicals. ${ }^{[2]}$ The effective transformation of methane, which constitutes the main component of natural gas, would accelerate the use of natural gas. ${ }^{[3]}$ The central challenges to methane functionalization lie in the intrinsical chemical inertness of the methane $\mathrm{C}-\mathrm{H}$ bonds and the accompanying side reactions of the desired products under the conditions necessary to activate methane due to their higher reactivity relative to that of methane itself..$^{[2 \mathrm{~b}-2 \mathrm{~d}]} \mathrm{The}$ industry currently uses the steam reforming process to convert methane to syngas, which can be further converted to higher hydrocarbons and methanol. However, the hydrocarbon and methanol formation processes involve breaking all the highly stable $\mathrm{C}-\mathrm{H}$ bonds of methane and the subsequent highly endothermic formation of $\mathrm{C}-\mathrm{H}$

* Corresponding author. E-mail: zuoweiwei@dhu.edu.cn

Received September 20, 2020; revised November 15, 2020; published online December 8, 2020.

Project supported by the National Natural Science Foundation of China (No. 21772021).

国家自然科学基金(No. 21772021)资助项目. 
bonds. ${ }^{[4]}$ This approach necessitates the management of unnecessarily excessive heat and, as a result, it is an energyand capital-intensive process. Therefore, the selective functionalization of only one $\mathrm{C}-\mathrm{H}$ bond of methane under mild conditions would be a significant advance.

Significant progress has been achieved in the development of new technologies towards the partial functionalization of methane with decreased capital investment. Metals (Pt, Hg, Pd etc. $)^{[5]}$ complex-catalyzed electrophilic substitution reactions in sulfuric and trifluoroacetic acid have resulted in the selectivity of methanol derivatives up to $98 \%$ with a highest methane turnover frequency of 25000 $\mathrm{h}^{-1}$. This is a very promising process, and provides that the separation of the product, the re-oxidation of $\mathrm{SO}_{2}$ and the possible inhibition of the catalytic performance by water are addressed. Methane can also be activated by heterogeneous catalysts with oxygen and $\mathrm{H}_{2} \mathrm{O}_{2}$ to produce oxygenated products, but the selectivity is generally relatively low due to the further oxidation of methanol by the oxidants, which is probably also catalyzed by the catalysts. ${ }^{[2 \mathrm{~d}]}$ The oxidative coupling of methane to ethane and ethylene ${ }^{[6]}$ and the nonoxidative aromatization of methane at high temperatures ${ }^{[7]}$ are also industrially significant, as far as the catalyst can operate under relatively milder reaction conditions and with higher product selectivity than that of other approaches.

Halogen-mediated methane functionalization has become an attractive route to methane transformation, ${ }^{[2 a, 8]}$ as it can enable selective methane $\mathrm{C}-\mathrm{H}$ bond scission to produce a mono-halogenated product that is deemed a versatile building block for a variety of chemical commodities. ${ }^{[2 c, 8 b, 8 f, 9]}$ High selectivity of methyl halides has been achieved by controlling the methane/halogen ratio of the feed gas in the direct halogenation process. However, this method necessitates the use of highly corrosive halogen gas and the subsequent re-oxidation of the hydrogen halide, ${ }^{[9 b]}$ which is unavoidably produced, in order to recycle the expensive halogen elements. The oxidative halogenation of methane, ${ }^{[8 \mathrm{~d}-8 \mathrm{f}, 10]}$ which integrates hydrogen halide oxidation and methane halogenation into a single step, is a significant advance. By controlling the methane/ $\mathrm{HBr}$ ratio at $693 \mathrm{~K}$ and using the good reactivity of vanadium phosphate catalysts, the production of methyl bromide with a selectivity of $91 \%$ has been achieved. ${ }^{[8 \mathrm{~d}-8 \mathrm{e}]}$ However, due to the chemical inertness of methane, these reactions usually proceed at relatively high temperature $\left(>400{ }^{\circ} \mathrm{C}\right)$ that will require heat management and increase the cost of the technology.

Trivalent iron complexes are known to undergo intramolecular ligand-to-metal charge transfer upon irradiation with ultraviolet and visible light to produce reactive radicals, such as $\mathrm{Cl} \cdot$, and reduced ferrous compound. ${ }^{[11]} \mathrm{As} \mathrm{H}-$ $\mathrm{Cl}$, for example, has a high bond dissociation energy (431.2 $\mathrm{kJ} / \mathrm{mol}$ ) that is only $8.4 \mathrm{~kJ} / \mathrm{mol}$ lower than that of methane $\mathrm{C}-\mathrm{H}$ bond, ${ }^{[12]}$ we envisioned that the transient chlorine radical generated by this photochemical process may initiate the functionalization of methane $\mathrm{C}-\mathrm{H}$ bonds via a hydrogen abstraction event at very mild conditions. In ad- dition, ferric halides are effective traps for alkyls radicals, leading to very fast reactions that produce alkyl halides and reduce metal halides. ${ }^{[13]}$ This fast reaction, probably thermodynamically driven by weak Fe-halide bonds (366.3 $\mathrm{kJ} / \mathrm{mol}$ for $\mathrm{Fe}-\mathrm{Cl}$, for example) in ferric halides, ${ }^{[14]}$ can compete with other potentially side reactions of alkyl radicals. Therefore, the methyl radical derived from the hydrogen abstraction event reacts quickly with an additional $\mathrm{FeCl}_{3}$ molecule to produce methyl chloride and ferrous chloride. This approach would establish a photochemical route to functionalize methane mediated by a less expensive salt (Eqs. $1 \sim 4$ ) than that typically used, and a catalytic variant can also be accessible if the reduced ferrous chloride can be re-oxidized to complete the iron loop. In this work, the selective chlorination of methane to methyl chloride with $\mathrm{FeCl}_{3}$ mediated by $\mathrm{FeCl}_{3}$ itself in the presence of ultraviolet light or solar light at ambient temperature is reported. The subsequent hydrolysis of methyl chloride to afford methanol and the re-oxidation of ferrous chloride with oxygen in the air in the presence of hydrogen chloride to recycle both iron and chlorine elements are also described. While the thermal-chemical ${ }^{[15]}$ and photochemi$\mathrm{cal}^{[11 \mathrm{~b}]}$ reactions of $\mathrm{FeCl}_{3}$ with higher alkanes have been tested, photochemical variants with methane have not been reported. The Miller process invoked the monobromination of methane with excellent selectivity by bromine, which was evolved in situ from molten $\mathrm{FeBr}_{3}$ dissolved in hydrated ferric chloride. However, no detailed experimental data were provided. ${ }^{[16]}$

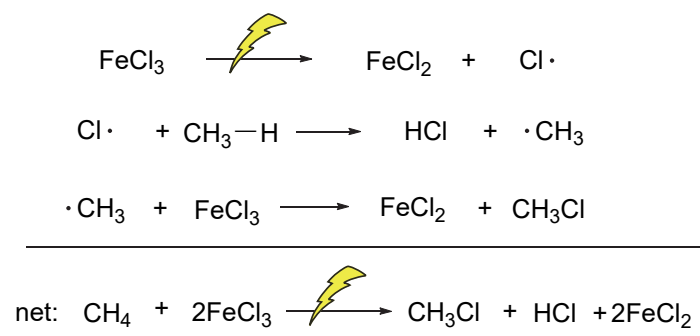

\section{Results and discussion}

The initial photochemical chlorination of methane (4 $\mathrm{MPa}$ ) was carried out at $25{ }^{\circ} \mathrm{C}$ by irradiating ferric chloride solution $\left(0.130 \mathrm{~mol} \cdot \mathrm{L}^{-1}\right)$ in acetonitrile with a 300 -watt high-pressure mercury lamp that was placed approximately $2 \mathrm{~cm}$ from the stainless-steel autoclave. After the reaction, the autoclave was cooled at $-78{ }^{\circ} \mathrm{C}$ for $\mathrm{ca} .30 \mathrm{~min}$ until the reaction mixture solidified, prior to the release of the high pressure of methane. The autoclave was then opened and removed from the cooling bath, and the solution was sampled for gas chromatography (GC) analysis immediately after thawing. GC analysis of the reaction solution indicates the formation of methyl chloride (Figure 1). The identity of methyl chloride was confirmed by a comparison of the GC chromatogram of the catalytic reaction and that of commercially purchased methyl chloride. No chloroform or carbon tetrachloride was formed. However, when acetoni- 
trile was used as the reaction medium, it was not possible to determine whether methylene chloride was also formed or not, because its peak was masked by that of acetonitrile in the GC chromatogram. ${ }^{1} \mathrm{H}$ NMR analysis of the reaction solution using deuterated acetonitrile $\left(\mathrm{CD}_{3} \mathrm{CN}\right)$ as the reaction solvent establishes the exclusive formation of methyl chloride (Figure 2). Further support for this high selectivity to the monochlorination product arose from analogous reactions of $\mathrm{FeCl}_{3}$ with other higher alkane, which produced chlorinated product that did not overlap with acetonitrile in the GC chromatogram. It turns out that in all cases only the mono-chlorinated products were produced. Therefore, a selective monochlorination of methane in acetonitrile is assumed because of the similarity of the reaction of methane to that of higher alkane. This selectivity is opposite to the

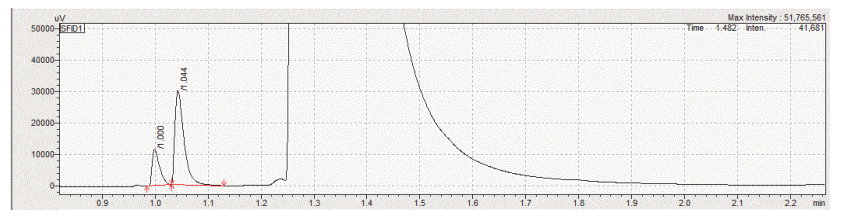

Figure $1 \mathrm{GC}$ chromatogram of the methyl chlorination reaction in $\mathrm{CH}_{3} \mathrm{CN}$

$\mathrm{GC}$ analysis conditions: oven temperature $\left(80{ }^{\circ} \mathrm{C}\right)$, SPL1 temperature $\left(275{ }^{\circ} \mathrm{C}\right)$; retention times: methane $1.000 \mathrm{~min}$, methyl chloride $1.044 \mathrm{~min}$, chloroform $1.784 \mathrm{~min}$, carbon tetrachloride $1.650 \mathrm{~min}$.
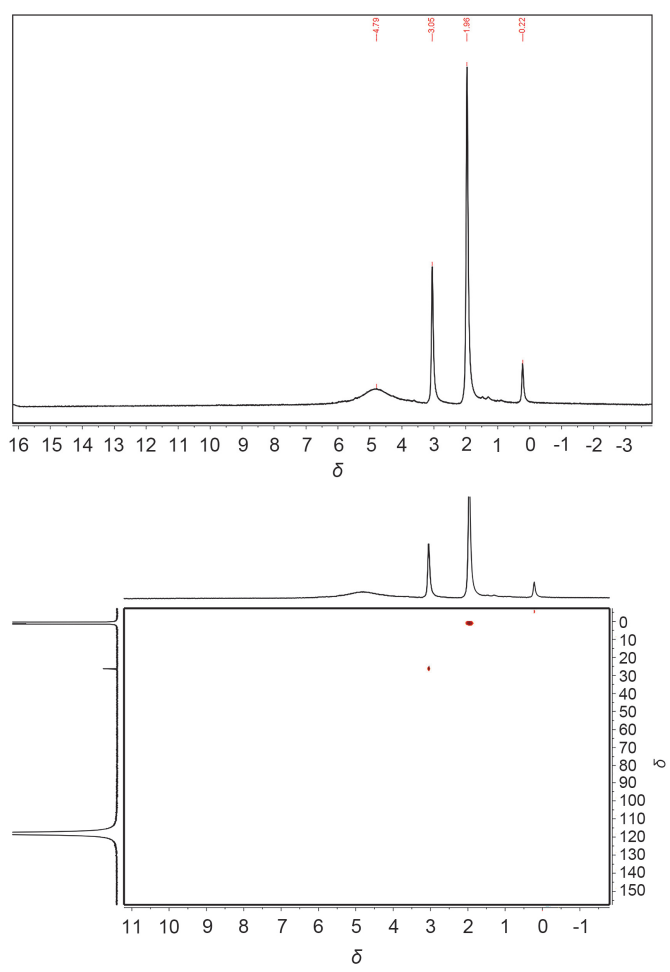

Figure $2{ }^{1} \mathrm{H}$ NMR $\left(600 \mathrm{MHz}, \mathrm{CD}_{3} \mathrm{CN}\right)$ and HSQC spectra of methyl chloride in acetonitrile- $d_{3}$ after being produced by a photochemical reaction in this solvent

In ${ }^{1} \mathrm{H}$ NMR spectrum, in addition to the signals at $\delta 0.22,3.05$ and 4.79 that are assigned to methane, methyl chloride and hydrogen chloride, respectively, no other resonances are observed, indicating no formation of methylene chloride, chloroform common view that radical reactions are not selective and that polychlorinated products usually dominate. This high selectivity could be accounted for by the polarity-matching effect, ${ }^{[17]}$ where the electron-withdrawing nature of the chloride substituent makes the $\mathrm{C}-\mathrm{H}$ bonds of the methyl group in methyl chloride less susceptible to hydrogen abstraction than those in methane. The similar electronwithdrawing nature of the $\mathrm{CN}$ group would also retard the hydrogen abstraction reaction on this molecule, thus making this solvent a suitable reaction medium for related reactions. Although in the GC chromatogram of this reaction, a small peak assigned to chloro-acetonitrile was detected. No methyl chloride was formed when either methane or ultraviolet light irradiation was omitted from the reaction mixture, indicating that methyl chloride originates from the photochemical reaction of methane.

The iron-based product was characterized by singlecrystal X-ray diffraction and Mössbauer spectroscopy. The bimetallic $\left[\mathrm{Fe}(\mathrm{MeCN})_{2} \mathrm{Cl}_{2}\right]_{2}$ molecular structure is shown in Figure 3, and a $298 \mathrm{~K}$ zero-field Mössbauer analysis of this product established a divalent iron center with an isomer shift of $1.08 \mathrm{~mm} / \mathrm{s}$ and a quadrupole splitting of 0.0137 $\mathrm{mm} / \mathrm{s}$. This result is consistent with the chemistry shown in Eq. 4, where ferric chloride serves as the stoichiometric oxidant for methane. The acidic nature of the reaction mixture (pH ca. 2 to 3 ) and the broad ${ }^{1} \mathrm{H}$ NMR signal at $\delta$ 4.79 that does not correlate to carbon nuclei in the corresponding heteronuclear singular quantum correlation (HSQC) spectrum indicates the formation of hydrogen chloride, although it has not been further characterized by other analytic techniques.

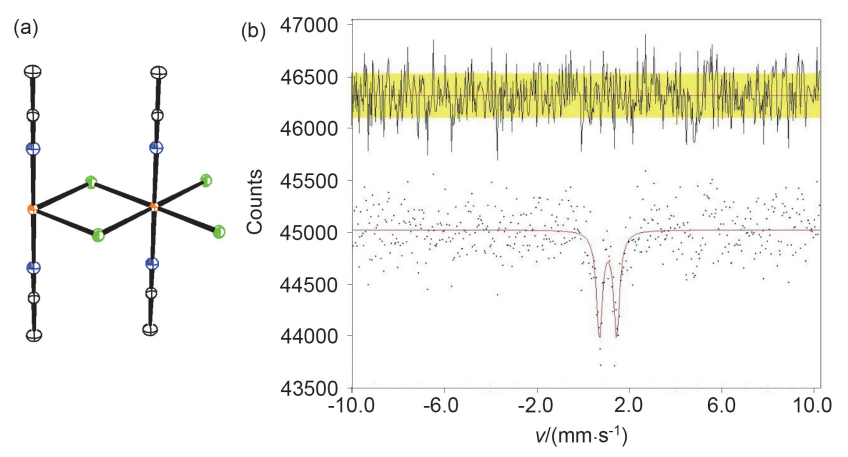

Figure 3 (a) Molecular structure of $\left[\mathrm{Fe}(\mathrm{MeCN})_{2} \mathrm{Cl}_{2}\right]_{2}$ produced by the photochemical reduction of $\mathrm{FeCl}_{3}$ in acetonitrile (Thermal ellipsoids are drawn at $30 \%$ probability) and (b) zero-field ${ }^{57} \mathrm{Fe}$ Mössbauer spectrum of $\left[\mathrm{Fe}(\mathrm{MeCN})_{2} \mathrm{Cl}_{2}\right]_{2}$ recorded at $298 \mathrm{~K}$

However, the amount of the formed methyl chloride could not be quantified, as methyl chloride is gaseous at room temperature, and not all of the methyl chloride gas left in the reaction solution after the release of the methane pressure can be sampled for GC analysis. The proportion of methyl chloride in the gaseous phase could not be determined by GC because of more than 1000-fold molar excess of methane over the potentially produced methyl chloride. Alternatively, the ferrous/ferric ratio of the solid after re- 
moving the solvent was analyzed to quantify the reaction rate. To confirm the effectiveness of using $\mathrm{FeCl}_{3}$ consumption as the indicator of methyl chloride production, analogous reaction with higher alkane was also carried out because the mono-chlorinated product produced from the higher alkane can be quantitatively determined by GC. It turns out that for cyclopentane, the consumption rate of $\mathrm{FeCl}_{3}$ equals the formation rate of chloro-cyclopentane, based on the stoichiometry described in Eq. 4, indicating that the photochemically generated chlorine radicals are fully transferred into the organic products.

The reaction profile in terms of $\mathrm{FeCl}_{3}$ conversion versus time indicates that, under the above conditions, the ferric conversion increased linearly with reaction time in the initial $10 \mathrm{~min}$ and then slowed until a maximum conversion of ca. 36\% was reached at $2 \mathrm{~h}$. A further increase in the reaction time only led to a slight increase in the ferric chloride conversion. The selectivity to methyl chloride was maintained with reaction time.

To gain further insight into this reaction, the impact of reaction parameters including the concentration of ferric chloride, the methane pressure and the power of the lamp on the initial reaction rate was evaluated (Figure 4). The initial reaction rate shows an approximately first-order dependence on the $\mathrm{FeCl}_{3}$ concentration in the range of 0.032 $0.065 \mathrm{~mol} \cdot \mathrm{L}^{-1}\left(0.0459\right.$ and $0.0591 \mathrm{~mol} \cdot \mathrm{L}^{-1} \cdot \mathrm{h}^{-1}$, respectively). The initial reaction rate increases with increasing iron concentration when $\mathrm{FeCl}_{3}$ concentration is $0.097 \mathrm{~mol}$ • $\mathrm{L}^{-1}\left(0.0716 \mathrm{~mol} \cdot \mathrm{L}^{-1} \cdot \mathrm{h}^{-1}\right)$. However, when the $\mathrm{FeCl}_{3}$ concentration is $0.130 \mathrm{~mol} \cdot \mathrm{L}^{-1}$, the reaction rate reaches to $0.0893 \mathrm{~mol} \cdot \mathrm{L}^{-1} \cdot \mathrm{h}^{-1}$, which increases faster than these with low iron concentration, and this concentration was chosen to explore the influence of other parameters. Interestingly, only a small fluctuation in the reaction rates was observed when the methane pressure ranged from $1 \sim 4 \mathrm{MPa}$, indicating that $\mathrm{C}-\mathrm{H}$ bond scission is not the slowest step in the overall reaction. The productivity was found to be not influenced by the reaction temperature in the range of $25 \sim$ $75{ }^{\circ} \mathrm{C}$. Compared to the typical high temperatures $(>$ $150{ }^{\circ} \mathrm{C}$ ) used in most of the reported technologies, the selective functionalization of methane at ambient temperature ${ }^{[18]}$ with readily available and inexpensive iron compounds used in this study represents a significant advance. High temperatures will lead to an additional investment in equipment and heat management, which will ultimately induce excessive investment costs. ${ }^{[19]}$ In addition, high temperatures easily lead to further combustion of the desired products, affording carbon oxides. As seen in Figure 4, the power of the light source was the second factor that had an obvious influence on the reaction rate; increasing the lamp power from 200 to $300 \mathrm{~W}$ led to an increase in the initial reaction rate by a factor of 2 . Thus, an initial methyl chloride productivity, derived from the $\mathrm{FeCl}_{3}$ consumption rate of $43 \mathrm{~g}_{\mathrm{MeCl}} \bullet\left(\mathrm{kg}_{\mathrm{Fe}} \bullet \mathrm{h}\right)^{-1}$ was obtained at $25{ }^{\circ} \mathrm{C}$ and 0.130 mol $\cdot \mathrm{L}^{-1} \mathrm{FeCl}_{3}$ with a methane pressure of $4 \mathrm{MPa}$ under 300 -watt high pressure mercury lamp within $1 \mathrm{~h}$. This value is approximately half of the production rate threshold [100
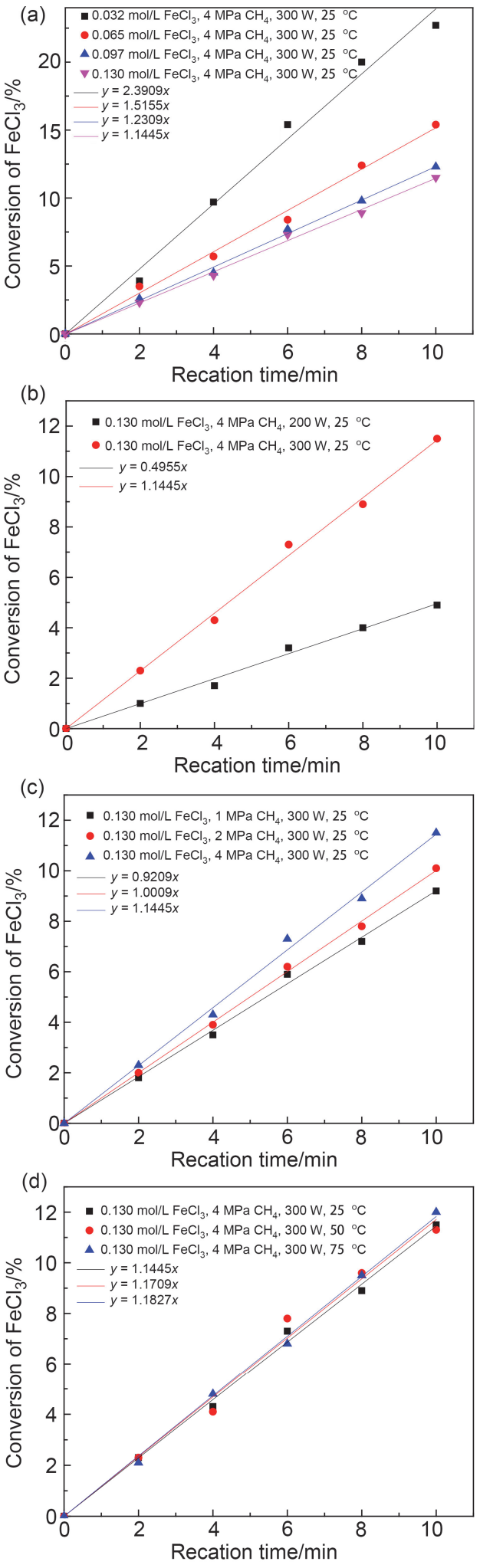

Figure 4 Effect of reaction parameters on the initial consumption rate of $\mathrm{FeCl}_{3}$ in the photochemical chlorination of methane (a) Effect of $\mathrm{FeCl}_{3}$ concentration. Conditions: acetonitrile as solvent, methane pressure $=4 \mathrm{MPa}, 25{ }^{\circ} \mathrm{C}, 300$-watt lamp; (b) effect of the power of the lamp. Conditions: $\left[\mathrm{FeCl}_{3}\right]=0.130 \mathrm{~mol} \cdot \mathrm{L}^{-1}$ in acetonitrile, methane pressure $=4 \mathrm{MPa}, 25{ }^{\circ} \mathrm{C}$; (c) effect of methane pressure. Conditions: $\left[\mathrm{FeCl}_{3}\right]=0.130 \mathrm{~mol} \cdot \mathrm{L}^{-1}$ in acetonitrile, $25{ }^{\circ} \mathrm{C}, 300$-watt lamp; (d) effect of reaction temperature. Conditions: $\left[\mathrm{FeCl}_{3}\right]=0.130 \mathrm{~mol} \cdot \mathrm{L}^{-1}$ in acetonitrile, methane pressure $=4 \mathrm{MPa}, 300$-watt lamp 
$\left.\mathrm{g} \bullet(\mathrm{kg} \bullet \mathrm{h})^{-1}\right]$ that is encountered in large-scale processes. ${ }^{[19 b, 20]}$ Note, however, this calculation does not take into account the cycle time of other separate steps including the re-oxidation of ferrous chloride, the hydrolysis of methyl chloride and potentially a distillation of methanol from the water solution in the hydrolysis step. ${ }^{[21]}$

These kinetic behaviors are consistent with the mechanism described in Eqs. $1 \sim 4$, which involves photochemical chlorine radical generation as the rate-determining step followed by fast methane $\mathrm{C}-\mathrm{H}$ bond functionalization. Chlorine radical was detected by GC-MS using 2,2,6,6tetramethylpiperidinooxy (TEMPO) as radical trap. These observations have also offered possible methods to further enhance the production of methyl chloride in the future, i.e., by either further increasing the power of the light source or substituting the solvent with a more suitable reaction medium in which ferric chloride has a higher solubility.

The photochemical chlorination of methane at $101 \mathrm{kPa}$ pressure was also carried out at $25{ }^{\circ} \mathrm{C}$ by irradiating a ferric chloride solution $\left(0.130 \mathrm{~mol} \cdot \mathrm{L}^{-1}\right)$ in acetonitrile with a 300-watt high-pressure mercury lamp that was placed approximately $15 \mathrm{~cm}$ from the flask. The solution was sampled for gas chromatography (GC) analysis immediately after $2 \mathrm{~h}$ of the reaction period and the release of the rest methane. And the conversion of $\mathrm{FeCl}_{3}$ was similar to that of $\mathrm{FeCl}_{3}$ with high pressure of methane. In addition, the exciting result was obtained that it could work for photochemical chlorination of methane at $101 \mathrm{kPa}$ pressure at $25{ }^{\circ} \mathrm{C}$. by irradiating a ferric chloride solution $(0.130 \mathrm{~mol} \cdot$ $\mathrm{L}^{-1}$ ) in acetonitrile with solar light. And the similar conversion of $\mathrm{FeCl}_{3}$ was observed.

The ferric oxidation state was readily regenerated by oxygen in the air in the presence of hydrochloride acid to close the iron loop. The ferrous complex, obtained from the photochemical reaction, reacts with hydrochloride acid in air at $120{ }^{\circ} \mathrm{C}$ for $c a .30 \mathrm{~min}$ to afford $\mathrm{H}_{2} \mathrm{FeCl}_{5}\left(\mathrm{H}_{2} \mathrm{O}\right.$ ) (Figure 5a) after crystallization from the reaction mixture. Formation of a trivalent iron complex was evidenced by the appearance of a $0.38 \mathrm{~mm} / \mathrm{s}$ isomer shift with a quadrupole splitting of $0.009 \mathrm{~mm} / \mathrm{s}$ in the $298 \mathrm{~K}$ Mössbauer spectrum (Figure 5b). When combined with the developed dehydration procedure of ferric chloride hydrate, ${ }^{[22]}$ the methane functionalization reaction can be rendered catalytic in terms of iron. In fact, $\mathrm{H}_{2} \mathrm{FeCl}_{5}\left(\mathrm{H}_{2} \mathrm{O}\right)$ is also active in mediating the chlorination of methane, at $25{ }^{\circ} \mathrm{C}$ and $0.130 \mathrm{~mol} \cdot \mathrm{L}^{-1}$ $\mathrm{H}_{2} \mathrm{FeCl}_{5}\left(\mathrm{H}_{2} \mathrm{O}\right)$ with a methane pressure of $4 \mathrm{MPa}$ under 300-watt high pressure mercury lamp irradiation, within 4 h, $13 \%$ ferric compounds were reduced to their ferrous counterparts, with a concomitant production of methyl chloride that was unambiguously detected by $\mathrm{GC}$ analysis. This lower reactivity than that of $\mathrm{H}_{2} \mathrm{FeCl}_{5}\left(\mathrm{H}_{2} \mathrm{O}\right)$ could be due to the decreased solubility of this ionic complex in acetonitrile. A similar decrease in reactivity with this ionic hydrate complex was also observed in the reactions of the higher alkane.

Methyl chloride serves as a versatile building block for the production of a series of valuable chemical commodit-

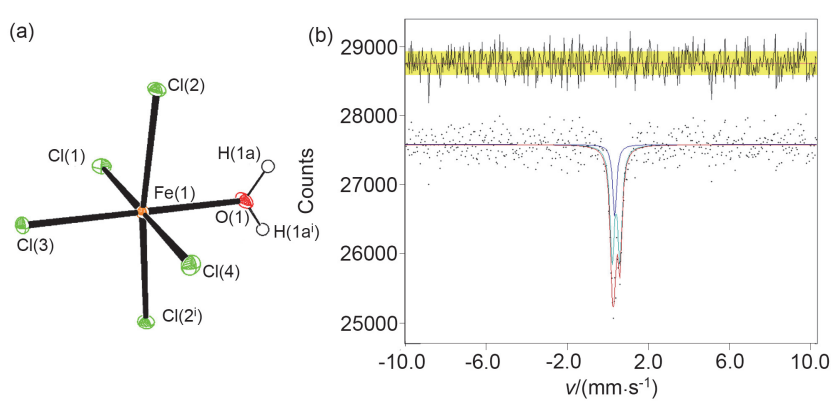

Figure 5 (a) Molecular structure of $\mathrm{H}_{2} \mathrm{Fe}\left(\mathrm{H}_{2} \mathrm{O}\right) \mathrm{Cl}_{5}$ produced by oxidation of $\left[\mathrm{Fe}(\mathrm{MeCN})_{2} \mathrm{Cl}_{2}\right]_{2}$ with air or hydrogen peroxide in dilute hydrochloric acid (Thermal ellipsoids are drawn at $30 \%$ probability) and (b) zero-field ${ }^{57} \mathrm{Fe}$ Mössbauer spectrum of $\mathrm{H}_{2} \mathrm{Fe}\left(\mathrm{H}_{2} \mathrm{O}\right) \mathrm{Cl}_{5}$ recorded at $298 \mathrm{~K}$

ies. ${ }^{[2 c, 8 b, 8 f, 9]}$ As a demonstration of the effectiveness of current technology, the methyl chloride was readily hydrolyzed to methanol and hydrogen chloride in a separate experiment using $\mathrm{Na}_{2} \mathrm{PtCl}_{4} / \mathrm{Na}_{2} \mathrm{PtCl}_{6}$ catalyst, following a patented procedure (Eq. 5). ${ }^{[23]}$ The reaction of methyl chloride $(0.25$ $\mathrm{MPa})$ and water $(3 \mathrm{~g})$ at $125{ }^{\circ} \mathrm{C}$ in a stainless-steel autoclave for $1 \mathrm{~h}$ affords methanol, which was confirmed by ${ }^{13} \mathrm{C}$ NMR analysis. Therefore, the combination of Eq. 4, this hydrolysis reaction and the cycling of ferric chloride (Eq. 6) led to a net reaction as shown in Eq. 7, where methane selectively reacts with water to produce methanol using air as the ultimate oxidant and $\mathrm{FeCl}_{3}$ as the catalyst.

$$
\begin{aligned}
& \mathrm{CH}_{3} \mathrm{Cl}+\mathrm{H}_{2} \mathrm{O} \longrightarrow \mathrm{CH}_{3} \mathrm{OH}+\mathrm{HCl} \\
& \mathrm{CH}_{4}+2 \mathrm{FeCl}_{3} \rightleftharpoons \mathrm{CH}_{3} \mathrm{Cl}+\mathrm{HCl}+2 \mathrm{FeCl}_{2} \\
& 2 \mathrm{FeCl}_{2}+2 \mathrm{HCl}+1 / 2 \mathrm{O}_{2} \text { (air) } \longrightarrow 2 \mathrm{FeCl}_{3}+\mathrm{H}_{2} \mathrm{O} \\
& \mathrm{CH}_{4}+1 / 2 \mathrm{O}_{2} \text { (air) } \rightleftharpoons \mathrm{CH}_{3} \mathrm{OH}
\end{aligned}
$$

In the direct halogenation process, the hydrogen halide byproduct must be recycled by an additional oxidant, i.e., oxygen in the air, due to the expensive nature of halogen, making this process costly. The recycling of $\mathrm{FeCl}_{3}$ in this protocol, however, could be easier and more economical than halogen cycling ${ }^{[10 a]}$ due to the relatively lower standard redox potential of $\mathrm{Fe}^{2+} / \mathrm{Fe}^{3+}$ than that of halide/halogen $\left(0.771 \mathrm{~V}\right.$ for $\mathrm{Fe}^{2+} / \mathrm{Fe}^{3^{+}}$vs $1.087 \mathrm{~V}$ for $2 \mathrm{Br}^{-} / \mathrm{Br}_{2}$ and 1.358 $\mathrm{V}$ for $\left.2 \mathrm{Cl}^{-} / \mathrm{Cl}_{2}\right)$ and the natural abundance of iron. In addition, combining this methane chlorination with methyl chloride hydrolysis and the more selective electrolysis of $\mathrm{FeCl}_{2}$ in the presence of $\mathrm{HCl}$, where $\mathrm{FeCl}_{2}$ is oxidized to $\mathrm{FeCl}_{3}$ at the anode and $\mathrm{HCl}$ is reduced to hydrogen at the cathode, may lead to a practical process for the selective hydroxylation and electrolytic reduction of methane to methanol and hydrogen. ${ }^{[24]}$ However, although the mild reaction conditions and high selectivity to methyl chloride are quite favorable for the scaling-up of this reaction. In addition to the currently relatively low productivity of methyl chloride, the current technology is still short of what is desired from a practical point of view. For example, the maximum concentration of methyl chloride calculated 
based on the maximum concentration of ferric chloride in acetonitrile is still quite lower than the threshold of large-scale production $\left(2 \mathrm{~mol} \cdot \mathrm{L}^{-1}\right) \cdot{ }^{[2 \mathrm{~d}, 21]} \mathrm{A}$ solvent is required that is compatible with this photochemical reaction and in which ferric chloride has a much higher solubility. And the test using solar light as the irradiation source has demonstrated the potential of using solar energy to mediate the reaction, although the productivity is also currently relatively low.

\section{Conclusions}

A route for a two-step conversion of methane to methanol via methyl chloride under mild conditions has been developed. Ferric chloride is an efficient mediator that in situ generates reactive chloride radicals upon irradiation with ultraviolet light or solar light and acts as the oxidant to produce methyl chloride. This process provides an extremely high methyl chloride selectivity $(>99 \%)$, with a maximum initial productivity of $43 \mathrm{~g}_{\mathrm{MeCl}}^{\bullet}\left(\mathrm{kg}_{\mathrm{Fe}} \bullet \mathrm{h}\right)^{-1}$. Methyl chloride can be further converted to methanol by hydrolysis with the elimination of $\mathrm{HCl}$, which reacts with ferrous chloride and oxygen in air to complete the loop of both iron and chlorine elements. The reaction rate could be further enhanced by increasing the power of light source and substituting with a solvent in which $\mathrm{FeCl}_{3}$ is more soluble. The updated reaction may pave the way for the economical, large-scale and selective functionalization of methane.

\section{Experimental section}

\subsection{Reagents and general methods}

$\mathrm{FeCl}_{3}(99 \%), \mathrm{Na}_{2} \mathrm{PtCl}_{6} \bullet 6 \mathrm{H}_{2} \mathrm{O}$ (Pt 34\%), $\mathrm{Na}_{2} \mathrm{PtCl}_{4} \bullet x \mathrm{H}_{2} \mathrm{O}$ (99\%) and $\mathrm{CH}_{3} \mathrm{CN}$ (99.9\%) were purchased from Adamas-beta. 2,2,6,6-Tetramethylpiperidinooxy (TEMPO, 98 $+\%$ ) was purchased from Alfa. $\mathrm{CD}_{3} \mathrm{CN}(99.8 \%)$ was purchased from Cambridge Isotope Laboratories, Inc. The solvent of $\mathrm{CH}_{3} \mathrm{CN}$ was dehydrated and deoxidized. $\mathrm{CH}_{4}$ (99.9\%) and $\mathrm{CH}_{3} \mathrm{Cl}$ (5\% in argon) were obtained from WenDong (Shanghai) Chemical Co., Ltd. Chloromethane standard solution $(1 \mathrm{mg} / \mathrm{mL}$ in $\mathrm{MeOH})$ was purchased from AccuStandard. NMR spectra were recorded at ambient temperature and pressure using BRUKER AVANCE III, HD $600 \mathrm{MHz}$ spectrometers $\left[{ }^{1} \mathrm{H}\right.$ NMR $(600 \mathrm{MHz}),{ }^{13} \mathrm{C}$ NMR (151 MHz)]. Single-crystal X-ray diffraction data were collected using a Nonius Kappa-CCD diffractometer with Mo K $\alpha$ radiation $(\lambda=0.071073 \mathrm{~nm})$ at Shanghai Institute of Organic Chemistry, Chinese Academy of Sciences. Crystallographic data for $\left[\mathrm{Fe}(\mathrm{MeCN})_{2} \mathrm{Cl}_{2}\right]_{2}$ (1978806) and $\mathrm{H}_{2} \mathrm{Fe}\left(\mathrm{H}_{2} \mathrm{O}\right) \mathrm{Cl}_{5}$ (1978813) were deposited at Cambridge Crystallographic Data Centre and are available free of charge from website https://www.ccdc.cam.ac.uk/.

4.2 Photochemical chlorination of methane in acetonitrile under high-pressure of methane and highpressure mercury lamp

In an argon glove box, $0.4 \mathrm{~g}$ of $\mathrm{FeCl}_{3}(2.47 \mathrm{mmol})$ and 15 $\mathrm{g}$ of $\mathrm{CH}_{3} \mathrm{CN}(19 \mathrm{~mL})$ were put into the quartz reaction vessel, which was taken out from the glove-box and placed in the chamber of the autoclave. The autoclave was fixed and then methane was introduced via the inflation inlet. The reaction solution was purged with methane 3 times prior to the reaction. The solution was irradiated by a 300 -watt high-pressure mercury lamp through the glass wall of the autoclave under stirring for pre-designed reaction time. After reaction, the solution was cooled at $-78{ }^{\circ} \mathrm{C}$ with an ethanol/dry ice mixture for $30 \mathrm{~min}$, followed by the release of the methane pressure. The auto-clave was open, and then the solution that condensed in the gap between the reaction vessel and the chamber of the autoclave was sampled for analysis, immediately after it thawed. A GC analysis of the reaction solution left inside the reaction vessel revealed the same result, although the direct analysis on the reaction solution that contains inorganic compounds may easily destroy the GC equipment.

4.3 Photochemical chlorination of methane in deuterated acetonitrile $\left(\mathrm{CD}_{3} \mathrm{CN}\right)$

The same procedure as that using non-deuterated acetonitrile at high pressure was employed except deuterated acetonitrile was used as solvent. The reaction was conducted at $25{ }^{\circ} \mathrm{C}$ for $2 \mathrm{~h}$, and the irradiation light was removed after the reaction. The autoclave was heated at $75{ }^{\circ} \mathrm{C}$ for $30 \mathrm{~min}$ and then cooled at $-78{ }^{\circ} \mathrm{C}$ for $30 \mathrm{~min}$. The autoclave was opened, and then the solution condensed in the gap between the reaction vessel and the chamber of autoclave was immediately sampled for NMR analysis after thawing.

4.4 Photochemical chlorination of methane in acetonitrile under atmospheric pressure of methane and high-pressure mercury lamp

In an argon glove box, $0.4 \mathrm{~g}$ of $\mathrm{FeCl}_{3}(2.47 \mathrm{mmol})$ and 15 $\mathrm{g}$ of $\mathrm{CH}_{3} \mathrm{CN}(19 \mathrm{~mL})$ were put into the $50 \mathrm{~mL}$ Schlenk flask, which was taken out from the glove-box and connected with a methane balloon. The solution was purged with methane at $101 \mathrm{kPa}$ for three times and then stirred at $101 \mathrm{kPa}$ pressure of methane for $5 \mathrm{~min}$ prior to the irradiation. The solution was irradiated for $2 \mathrm{~h}$ by a 300 -watt high-pressure mercury lamp that was placed around $15 \mathrm{~cm}$ away. After reaction, the lamp was removed and the solution was further stirred at $0{ }^{\circ} \mathrm{C}$ for additional 10 min prior to the remove of the balloon and the release of the pressure. The solution was filtered and quantitatively diluted with pure acetonitrile into a vial for $\mathrm{GC}$ analysis.

4.5 Photochemical chlorination of methane in acetonitrile under atmospheric pressure of methane and solar light

In an argon glove box, $0.4 \mathrm{~g}$ of $\mathrm{FeCl}_{3}(2.47 \mathrm{mmol})$ and 15 $\mathrm{g}$ of $\mathrm{CH}_{3} \mathrm{CN}(19 \mathrm{~mL})$ were put into the $50 \mathrm{~mL}$ Schlenk flask, which was taken out from the glove-box and connected with a methane balloon. The solution was purged with methane at $101 \mathrm{kPa}$ for three times and then stirred at $101 \mathrm{kPa}$ pressure of methane for $5 \mathrm{~min}$ prior to the irradiation under the noon solar light. The solution was irradiated for $2 \mathrm{~h}$ by 
solar light. After reaction, the solution was further stirred at $0{ }^{\circ} \mathrm{C}$ for additional $10 \mathrm{~min}$ in the dark prior to the remove of the balloon and the release of the pressure. The solution was filtered and quantitatively diluted with pure acetonitrile into a vial for GC analysis.

\subsection{Isolation and characterization of iron-based product}

The single crystals of the iron-based product suitable for $\mathrm{X}$-ray diffraction were obtained by slow diffusion of diethyl ether into the reaction solution, which has the highest conversion of $\mathrm{FeCl}_{3}$ after an irradiation of over $2 \mathrm{~h}$.

4.7 Oxidation of ferrous chloride complex to the ferric analog with oxygen in the air in the presence of hydrochloride acid

After a typical methane chlorination reaction that use 0.4 $\mathrm{g}$ of $\mathrm{FeCl}_{3}(2.47 \mathrm{mmol}), 15 \mathrm{~g}$ of $\mathrm{CH}_{3} \mathrm{CN}$ and $4 \mathrm{MPa}$ methane, the reaction solution was poured into a round-bottom flask. $5 \mathrm{~mL}$ of $\mathrm{H}_{2} \mathrm{O}$ and $1 \mathrm{~mL}$ concentrated hydrochloride acid $(37.5 \%)$ were added. The solution was then heated at $120{ }^{\circ} \mathrm{C}$ for $30 \mathrm{~min}$ in the air. If the reaction was conducted with $\mathrm{H}_{2} \mathrm{O}_{2}, 5 \mathrm{~mL}$ of $\mathrm{H}_{2} \mathrm{O}_{2}\left(30 \%\right.$ in $\left.\mathrm{H}_{2} \mathrm{O}\right)$ was added. After reaction, the volatiles were removed by rotary evaporator and the solid obtained were used for further chlorination reaction. Single crystals suitable for X-ray analysis were obtained by recrystallization from the reaction mixture.

\subsection{Hydrolysis of chloromethane}

In an argon glove box, $0.67 \mathrm{~g}$ of $\mathrm{NaPtCl}_{6} \cdot 6 \mathrm{H}_{2} \mathrm{O}(1.2$ mmol) and $0.062 \mathrm{~g}$ of $\mathrm{NaPtCl}_{4} \bullet x \mathrm{H}_{2} \mathrm{O}(0.16 \mathrm{mmol})$ were put into the quartz reaction vessel. This vessel was taken out from the glovebox and $3 \mathrm{~g}$ of $\mathrm{H}_{2} \mathrm{O}$ was added. The vessel was then placed in the chamber of the autoclave and the autoclave was sealed. $5 \mathrm{MPa}$ of gas mixture that contains $5 \% \mathrm{CH}_{3} \mathrm{Cl}$ and $95 \%$ argon was filled and then the auto-clave was heated at $125^{\circ} \mathrm{C}$ for $1 \mathrm{~h}$ with stirring. After reaction, the autoclave was cooled at $0{ }^{\circ} \mathrm{C}$ for $30 \mathrm{~min}$. The high pressure was released and then the autoclave was opened. The solution that was condensed in the gap between the reaction vessel and the chamber of the auto-clave was sampled for ${ }^{13} \mathrm{CNMR}$ analysis with using a $\mathrm{D}_{2} \mathrm{O}$ insert for locking nd shimming, from which a signal at $\delta 48.98$ was assigned to methanol.

\subsection{Cyclic experiment}

After a typical methane chlorination reaction that use 0.4 $\mathrm{g}$ of $\mathrm{FeCl}_{3}(2.47 \mathrm{mmol}), 15 \mathrm{~g}$ of $\mathrm{CH}_{3} \mathrm{CN}$ and $4 \mathrm{MPa}$ methane and oxidation of ferrous chloride complex in the reaction solution to the ferric analog with oxygen in the air in the presence of hydrochloride acid, the obtained complex was used to chlorinate methane again. And after chlorination, the complex underwent oxidation. This cycle conducted 6 times. Then the final iron complex was tested, and it turned out that $12 \%$ of ferric iron was converted to ferrous iron.

\subsection{Detection of $\mathrm{Cl}$ radical}

In an argon glove box, $0.4 \mathrm{~g}$ of $\mathrm{FeCl}_{3}(2.47 \mathrm{mmol}), 0.77 \mathrm{~g}$ of TEMPO (4.93 mmol) and $15 \mathrm{~g}$ of $\mathrm{CH}_{3} \mathrm{CN}(19 \mathrm{~mL})$ were put into the $50 \mathrm{~mL}$ Schlenk flask, which was taken out from the glove-box and connected with a methane balloon. The solution was purged with methane at $101 \mathrm{kPa}$ for three times and then stirred at $101 \mathrm{kPa}$ pressure of methane for $5 \mathrm{~min}$ prior to the irradiation. The solution was irradiated for $2 \mathrm{~h}$ by a 300-watt high-pressure mercury lamp that was placed around $15 \mathrm{~cm}$ away. After reaction, the lamp was removed and the solution was further stirred at $0{ }^{\circ} \mathrm{C}$ for additional 10 min prior to the remove of the balloon and the release of the pressure. The solution was filtered and quantitatively diluted with pure acetonitrile into a vial for GC-MS analysis.

Supporting Information Setups for chlorination of methane under high-pressure/atmospheric pressure of methane, GC chromatograms, NMR spectra, determination of the ratio of $\mathrm{Fe}^{2+} / \mathrm{Fe}^{3+}$ with spectrophotometric method, chlorination of cyclopentane. The Supporting Information is available free of charge via the Internet at http://siocjournal.cn.

\section{References}

[1] Lamarche-Gagnon, G.; Wadham, J. L.; Sherwood Lollar, B.; Arndt, S.; Fietzek, P.; Beaton, A. D.; Tedstone, A. J.; Telling, J.; Bagshaw, E. A.; Hawkings, J. R.; Kohler, T. J.; Zarsky, J. D.; Mowlem, M. C.; Anesio, A. M.; Stibal, M. Nature 2019, 565, 73.

[2] (a) McFarland, E. Science 2012, 338, 340.

(b) Gunsalus, N. J.; Koppaka, A.; Park, S. H.; Bischof, S. M.; Hashiguchi, B. G.; Periana, R. A. Chem. Rev. 2017, 117, 8521.

(c) Lin, R.; Amrute, A. P.; Perez-Ramirez, J. Chem. Rev. 2017, 117, 4182.

(d) Ravi, M.; Ranocchiari, M.; van Bokhoven, J. A. Angew. Chem., Int. Ed. 2017, 56, 16464.

[3] (a) Fletcher, S. E. M.; Schaefer, H. Science 2019, 364, 932.

(b) Labinger, J. A.; Bercaw, J. E. Nature 2002, 417, 507

(c) Shilov, A. E.; Shul'pin, G. B. Chem. Rev. 1997, 97, 2879.

(d) Cavaliere, V. N.; Wicker, B. F.; Mindiola, D. J. Adv. Organomet. Chem. 2012, 60, 1 .

[4] (a) Alvarez-Galvan, M. C.; Mota, N.; Ojeda, M.; Rojas, S.; Navarro, R. M.; Fierro, J. L. G. Catal. Today 2011, 171, 15.

(b) Olsbye, U. Angew. Chem., Int. Ed. 2016, 55, 7294.

[5] (a) Zimmermann, T.; Soorholtz, M.; Bilke, M.; Schuth, F. J. Am. Chem. Soc. 2016, 138, 12395.

(b) Periana, R. A.; Taube, D. J.; Evitt, E. R.; Loffler, D. G.; Wentrcek, P. R.; Voss, G.; Masuda, T. Science 1993, 259, 340.

(c) Periana, R. A.; Taube, D. J.; Gamble, S.; Taube, H.; Satoh, T.; Fujii, H. Science 1998, 280, 560.

(d) Lin, M.; Sen, A. Nature 1994, 368, 613.

(e) Periana, R. A.; Mironov, O.; Taube, D.; Bhalla, G.; Jones, C. J. Science 2003, 301, 814.

(f) Gretz, E.; Oliver, T. F.; Sen, A. J. Am. Chem. Soc. 1987, 109, 8109.

(g) Vargaftik, M. N.; Stolarov, I. P.; Moiseev, I. I. J. Chem. Soc., Chem. Commun. 1990, 1049.

(h) Kao, L. C.; Hutson, A. C.; Sen, A. J. Am. Chem. Soc. 1991, 113, 700 .

[6] (a) Takanabe, K.; Iglesia, E. Angew. Chem., Int. Ed. 2008, 47, 7689. (b) Hammond, C.; Conrad, S.; Hermans, I. ChemSusChem 2012, 5, 1668 .

(c) Lunsford, J. H. Angew. Chem., Int. Ed. Engl. 1995, 34, 970.

(d) Meng, L.; Chen, Z.; Ma, Z.; He, S.; Hou, Y.; Li, H.-H.; Yuan, R.; Huang, X.-H.; Wang, X.; Wang, X.; Long, J. Energy Environ. Sci. 2018, 11, 294.

(e) Wu, S.; Tan, X.; Lei, J.; Chen, H.; Wang, L.; Zhang, J. J. Am. 
Chem. Soc. 2019, 141, 6592

[7] Horn, R.; Schloegl, R. Catal. Lett. 2015, 145, 23.

[8] (a) Bilke, M.; Losch, P.; Vozniuk, O.; Bodach, A.; Schuth, F. J. Am. Chem. Soc. 2019, 141, 11212.

(b) Olah, G. A.; Gupta, B.; Farina, M.; Felberg, J. D.; Ip, W. M.; Husain, A.; Karpeles, R.; Lammertsma, K.; Melhotra, A. K.; Trivedi, N. J. J. Am. Chem. Soc. 1985, 107, 7097.

(c) Zhou, X. P.; Yilmaz, A.; Yilmaz, G. A.; Lorkovic, I. M.; Laverman, L. E.; Weiss, M.; Sherman, J. H.; McFarland, E. W.; Stucky, G. D.; Ford, P. C. Chem. Commun. 2003, 2294.

(d) Paunovic, V.; Zichittella, G.; Moser, M.; Amrute, A. P.; Perez-Ramirez, J. Nat. Chem. 2016, 8,803 .

(e) Podkolzin, S. G.; Stangland, E. E.; Jones, M. E.; Peringer, E.; Lercher, J. A. J. Am. Chem. Soc. 2007, 129, 2569.

(f) He, J.; Xu, T.; Wang, Z.; Zhang, Q.; Deng, W.; Wang, Y. Angew. Chem., Int. Ed. 2012, 51, 2438.

[9] (a) Li, F.; Yuan, G. Angew. Chem., Int. Ed. 2006, 45, 6541. (b) Batamack, P. T. D.; Mathew, T.; Prakash, G. K. S. J. Am. Chem. Soc. 2017, 139, 18078.

[10] (a) Paunovic, V.; Lin, R.; Scharfe, M.; Amrute, A. P.; Mitchell, S.; Hauert, R.; Perez-Ramirez, J. Angew. Chem., Int. Ed. 2017, 56, 9791

(b) Shalygin, A.; Paukshtis, E.; Kovalyov, E.; Bal'Zhinimaev, B. Front. Chem. Sci. Eng. 2013, 7, 279.

[11] (a) Maldotti, A.; Molinari, A.; Amadelli, R. Chem. Rev. 2002, 102, 3811 .

(b) Wu, W.; Fu, Z.; Wen, X.; Wang, Y.; Zou, S.; Meng, Y.; Liu, Y.; Kirk, S. R.; Yin, D. Appl. Catal. A: Gen. 2014, 469, 483.

[12] Blanksby, S. J.; Ellison, G. B. Acc. Chem. Res. 2003, 36, 255.

[13] (a) Minisci, F.; Fontana, F. Tetrahedron Lett. 1994, 35, 1427.

(b) Kochi, J. K. Science 1967, 155, 415.
[14] Bach, R. D.; Shobe, D. S.; Schlegel, H. B.; Nagel, C. J. J. Phys. Chem. 1996, 100, 8770.

[15] Chang, P. K. A. J.-H. C. J. Org. Chem. 1971, 36, 3138.

[16] Miller, J. WO 9959946, 1999.

[17] (a) Roberts, B. P. Chem. Soc. Rev. 1999, 28, 25.

(b) Le, C.; Liang, Y.; Evans, R. W.; Li, X.; Mac-Millan, D. W. C. Nature 2017, 547, 79.

[18] (a) Sorokin, A. B.; Kudrik, E. V.; Alvarez, L. X.; Afanasiev, P.; Millet, J. M. M.; Bouchu, D. Catal. Today 2010, 157, 149.

(b) An, Z.-J.; Pan, X.-L.; Liu, X.-M.; Han, X.-W.; Bao, X.-H. J. Am. Chem. Soc. 2006, 128, 16028.

(c) Bar-Nahum, I.; Khenkin, A. M.; Neumann, R. J. Am. Chem. Soc. 2004, 126, 10236.

(d) Muehlhofer, M.; Strassner, T.; Herrmann, W. A. Angew. Chem., Int. Ed. 2002, 41, 1745.

(e) Kirillova, M. V.; Kuznetsov, M. L.; Reis, P. M.; da Silva, J. A. L.; da Silva, J. J. R. F.; Pombeiro, A. J. L. J. Am. Chem. Soc. 2007, 129, 10531.

[19] (a) Lange, J.-P. ChemSusChem 2017, 10, 245.

(b) Lange, J. P. CATTECH 2001, $5,82$.

[20] Lange, J.-P. Catal. Sci. Technol. 2016, 6, 4759.

[21] Lange, J.-P.; Sushkevich, V. L.; Knorpp, A. J.; van Bokhoven, J. A. Ind. Eng. Chem. Res. 2019, 58, 8674.

[22] Knuuttila, P. T.; Jokinen, S. S.; Judin, V. O.; Vuorisalo, J. T.; Salanne, S. S. EP 0493023, 1992.

[23] Horvath, I. T.; Pa, N. H.; Summit, J. M. M.; Cook, R. A. US $5354916,1994$.

[24] Mizuta, S.; Kondo, W.; Fujii, K.; Iida, H.; Isshiki, S.; Noguchi, H.; Kikuchi, T.; Sue, H.; Sakai, K. Ind. Eng. Chem. Res. 1991, 30, 1601. 